\title{
Emergency obstetric hysterectomy: a two-year observational study at tertiary care center in Berhampur, Odisha, India
}

\author{
Ritanjali Behera, Bibekananda Rath*
}

Department of Obstetrics and Gynecology, MKCG Medical College and Hospital, Berhampur, Odisha, India

Received: 24 October 2019

Accepted: 08 November 2019

\section{*Correspondence:}

Dr. Bibekananda Rath,

E-mail: dr.sourav83@gmail.com

Copyright: (C) the author(s), publisher and licensee Medip Academy. This is an open-access article distributed under the terms of the Creative Commons Attribution Non-Commercial License, which permits unrestricted non-commercial use, distribution, and reproduction in any medium, provided the original work is properly cited.

\begin{abstract}
Background: Emergency obstetric hysterectomy is an unequivocal marker of severe maternal morbidity and, in many respects, the treatment of last resort for rupture uterus, severe postpartum hemorrhage (PPH) and other such lifethreatening conditions. In no other gynaecological or obstetrical surgery is the surgeon in as much a dilemma as when deciding to resort to an emergency hysterectomy. On one hand it is the last resort to save a mother's life, and on the other hand, the mother's reproductive capability is sacrificed. This study is conducted with an aim to determine the frequency, demographic characteristics, indications, and feto-maternal outcomes associated with emergency obstetric hysterectomy in a tertiary care centre.

Methods: We conducted a prospective, observational, and analytical study over a period of two years, from September 2017 till September 2019. A total of 56 cases of emergency obstetric hysterectomy (EOH) were studied in the Department of Obstetrics and Gynecology, MKCG Medical College, Berhampur.

Results: The incidence of EOH in our study was 12 following vaginal delivery and 44 following caesarean section. The overall incidence was 56 per 21,128 deliveries. Uterine rupture (37.5\%) was the most common indication followed by atonic postpartum hemorrhage $(25 \%)$ and placenta accrete spectrum $(10.7 \%)$. The most frequent sequelae were febrile morbidity $(25.7 \%)$ and disseminated intravascular coagulation (21.4\%). Maternal mortality was $17.1 \%$ whereas perinatal mortality was $51.7 \%$.

Conclusions: A balanced approach to EOH can prove to be lifesaving at times when conservative surgical modalities fail and interventional radiology is not immediately available. Our study highlights the place of extirpative surgery in modern obstetrics in the face of rising rates of caesarean section and multiple pregnancies particularly in urban settings in developing countries.
\end{abstract}

Keywords: Emergency obstetric hysterectomy, Extirpative surgery, Interventional radiology, Placenta acreta spectrum

\section{INTRODUCTION}

Emergency obstetric hysterectomy (EOH) is defined as extirpation of the uterus either at the time of caesarean section or following vaginal delivery, or within the puerperium period. It is usually performed in the face of unrelenting and life-threatening obstetric hemorrhage. A near miss event is defined as a woman who nearly died but survived a complication that occurred during pregnancy, childbirth, or within 42 days of termination of pregnancy. ${ }^{1} \mathrm{EOH}$ can be rightly classified as a near miss event. It is important to study such events since they provide an insight into the standard of care provided and help to reduce maternal morbidity and mortality. 
Conservative methods such as community-based use of oxytocin, misoprostol, carboprost, bimanual uterine compression, condom catheter balloon, and noninflatable anti-shock garments for the management of atonic PPH have all been advocated to effectively manage obstetric hemorrhage in low resource settings. ${ }^{2}$ Advances in interventional radiology have also provided the option of uterine artery embolization. ${ }^{3,4}$

The purpose of our study was to know the incidence, indications, risk factors and the maternal complications of the patients undergoing emergency obstetric hysterectomies at our tertiary level hospital which mainly caters to the rural and urban population.

\section{METHODS}

This is a prospective, observational, analytical study of women requiring emergency obstetric hysterectomy $(\mathrm{EOH})$ for some indication during pregnancy, labor and puerperium. We recorded the data for over a period of two years, from September 2017 to September 2019 in the Department of Obstetrics and Gynecology, MKCG Medical College and Hospital, Odisha, India.

EOH was defined as hysterectomy performed for hemorrhage unresponsive to other therapeutic interventions, such as shock following ruptured ectopic pregnancy, perforation after medical termination of pregnancy, vaginal delivery, cesarean section, sepsis or within the period of puerperium. Inclusion criteria included all women who were admitted to the hospital during the two-year study period in their pregnancy and underwent hysterectomy for some obstetric indication at the time of pregnancy, delivery or subsequently within the defined period of puerperium (42 days). During this period 21,128 deliveries were conducted and 56 patients underwent emergency hysterectomy. All women those who had undergone termination of pregnancy or had delivered outside the hospital and were referred for obstetric complications meriting a hysterectomy and fulfilling all the above conditions were also included in the study. Women undergoing hysterectomy for indications other than obstetric, or outside the stipulated time of 42 days post-delivery were excluded from the study.

After collecting relevant data from patient's history, operation theatre records and case records, through scrutiny was done with regard to incidence, age, parity, antenatal high-risk factors, indications, hysterectomy type, and complications, along with the ultimate fetomaternal outcome. Institutional ethical committee approval was obtained for the study.

\section{RESULTS}

Total number of deliveries conducted in MKCG Medical College during the 2 years period (September 2017 to September 2019) was 21,128.
Table 1: Incidence of emergency obstetric hysterectomies (EOH) following vaginal delivery and cesarean section.

\begin{tabular}{|llll|}
\hline Mode of delivery & $\begin{array}{l}\text { Number } \\
\text { of patients }\end{array}$ & EOH & $\begin{array}{l}\text { Incidence } \\
(\%)\end{array}$ \\
\hline $\begin{array}{l}\text { Normal vaginal } \\
\text { delivery }\end{array}$ & 11916 & 12 & 0.001 \\
\hline Cesarean section & 9212 & 44 & 0.477 \\
\hline Total & $\mathbf{2 1 1 2 8}$ & $\mathbf{5 6}$ & $\mathbf{0 . 2 6 5}$ \\
\hline
\end{tabular}

Out of 21,128 deliveries, the incidence of obstetric hysterectomy in our study was $0.001 \%$ (1 hysterectomy per 1000 deliveries) following vaginal delivery, and $0.477 \%$ (4.7 hysterectomies per 1000 deliveries) following cesarean section. The overall incidence was $0.265 \%$ (2.65 hysterectomies per 1000 deliveries). The cesarean section rate during the study period was $43.6 \%$ (Table 1).

Table 2: Antenatal booking.

\begin{tabular}{|lll|}
\hline Booking status & Number & Percentage (\%) \\
\hline Registered & 20 & $35.7 \%$ \\
\hline Unregistered & 36 & $64.3 \%$ \\
\hline
\end{tabular}

Out of total 56 cases of obstetric hysterectomies thirty-six cases were not booked (64.3\%), mostly constituted rural population and twenty booked $(35.7 \%)$ cases were almost equally distributed between rural and urban population (Table 2).

Table 3: Age and parity distribution of women included in the study.

\begin{tabular}{|lllllll|}
\hline \multicolumn{1}{|c|}{ Age (years) } & \multicolumn{1}{c|}{ Parity } \\
\hline $15-20$ & 1 & 1 & 0 & 0 & 0 & 2 \\
\hline $20-25$ & 6 & 10 & 2 & 0 & 0 & 18 \\
\hline $25-30$ & 3 & 6 & 9 & 2 & 0 & 20 \\
\hline $30-35$ & 1 & 2 & 3 & 1 & 2 & 9 \\
\hline $35-40$ & 0 & 0 & 4 & 2 & 1 & 7 \\
\hline Total & $\mathbf{1 1}$ & $\mathbf{1 9}$ & $\mathbf{1 8}$ & $\mathbf{5}$ & $\mathbf{3}$ & $\mathbf{5 6}$ \\
\hline
\end{tabular}

The youngest woman to undergo obstetric hysterectomy was 18 years old and the oldest was aged 37 years. Women in the 20 to 30 years age group constituted over $67 \%$ of cases, and $80 \%$ of the cases were multiparous (Table 3).

Most common risk factor found in this study was history of previous caesarean section $(64.8 \%)$ followed by increasing maternal age (ie. age > 35 years) $(18.9 \%)$ (Table 4).

Of the 56 cases of EOH studied, $94 \%$ of deliveries were institutional where as $6 \%$ of patients delivered outside the hospital and were later referred for further management. Uterine rupture, uterine atony and placenta acreta 
spectrum were the three chief indications for the procedure (Table 5). Rupture uterus was the indication for $\mathrm{EOH}$ in 21 cases, mostly because of attempted vaginal delivery by the patient at home and secondly poor referral system. It was associated with previous single cesarean in 15 cases, previous double caesarean in 2 cases and with grand multiparity, prolonged labor, sepsis and multifetal gestation in one case each.

Table 4: Risk factors associated with obstetric hysterectomy.

\begin{tabular}{|lll|}
\hline Risk factors & Number & $\%$ \\
\hline Age $>35$ years & 7 & $18.9 \%$ \\
\hline H/o Previous ceserean section & 24 & $64.8 \%$ \\
\hline H/o Myomectomy & 2 & $5.4 \%$ \\
\hline Multiple pregnancy & 1 & $2.7 \%$ \\
\hline IVF* conception & 1 & $2.7 \%$ \\
\hline Traumatic & 2 & $5.4 \%$ \\
\hline
\end{tabular}

*IVF- in vitro fertilisation.

Table 5: Indications of emergency obstetric hysterectomy in the study population.

\begin{tabular}{|lll|}
\hline Indication & Number & $\%$ \\
\hline Uterine rupture & 21 & 37.5 \\
\hline Atonic postpartum hemorrhage & 14 & 25 \\
\hline Placenta acreta spectrum & 6 & 10.7 \\
\hline Abruptio placentae & 5 & 8.9 \\
\hline Placenta previa & 4 & 7.1 \\
\hline Other* & 6 & 10.8 \\
\hline Total & $\mathbf{5 6}$ & $\mathbf{1 0 0}$ \\
\hline
\end{tabular}

*Three cases of extensive extension of uterine scar; two cases of broad ligament hematoma; and one case of perforation of uterus during MTP.
Uterine atonic postpartum hemorrhage was the cause in 14 cases. It was associated with obstructed labour in five cases, previous caesarean in three cases, with anemia in three cases, with a distended uterus as in multiple pregnancy or polyhydramnios in one cases each, and with placental cause in one case.

Placenta acreta spectrum was the indication for EOH in 6 cases and was associated with one or more cesarean sections previously in 3 cases, previous curettage in one case, and with a history of manual removal of the placenta and fibroid uterus in one case each. More than one factor was associated in many cases, for example, one woman had history of prior caesarean section and also prior curettage.

Table 6: Feto-maternal complications.

\begin{tabular}{|lll|}
\hline Maternal complications & Number & $\%$ \\
\hline Intra-op complications & 28 & $73.7 \%$ \\
\hline Shock & 6 & $15.8 \%$ \\
\hline Bladder injury & 2 & $5.26 \%$ \\
\hline Broad ligament hematoma & 2 & $5.26 \%$ \\
\hline Cervical injury & & \\
\hline Postop complications & 18 & $25.7 \%$ \\
\hline Fever & 15 & $21.4 \%$ \\
\hline DIC & 7 & $10 \%$ \\
\hline Septicaemia & 7 & $10 \%$ \\
\hline Wound infection & 6 & $8.5 \%$ \\
\hline Respiratory tract infection & 5 & $7.1 \%$ \\
\hline Acute renal failure & 12 & $17.1 \%$ \\
\hline Mortality & & \\
\hline Fetal complications & 26 & $46.2 \%$ \\
\hline NICU admission for birth asphyxia & 26 & $51.7 \%$ \\
\hline Mortality & 29 & \\
\hline
\end{tabular}

Table 7: Total transfusion of blood products.

\begin{tabular}{|lllll|}
\hline Indication & Number & $\begin{array}{l}\text { Packed cell units } \\
\text { total (Avg.) }\end{array}$ & $\begin{array}{l}\text { Fresh frozen plasma } \\
\text { units total (Avg.) }\end{array}$ & $\begin{array}{l}\text { Platelet units total } \\
\text { (Avg.) }\end{array}$ \\
\hline Uterine rupture & 21 & $66(3.1)$ & $52(2.47)$ & $8(0.57)$ \\
\hline Atonic postpartum hemorrhage & 14 & $54(3.8)$ & $49(3.5)$ & $13(2.16)$ \\
\hline Placenta acreta spectrum & 6 & $15(2.5)$ & $16(3.2)$ & $4(2)$ \\
\hline Abruptio placentae & 5 & $18(3.6)$ & $6(1.5)$ & $4.66)$ \\
\hline Placenta previa & 4 & $10(2.5)$ & $16(2.66)$ & $\mathbf{2 2}(\mathbf{0 . 3 9})$ \\
\hline Others & 6 & $29(3.3)$ & $\mathbf{1 3 0}(\mathbf{2 . 3 2})$ & \\
\hline Total & $\mathbf{5 6}$ & $\mathbf{1 8 3}(\mathbf{3 . 2 6})$ & & \\
\hline
\end{tabular}

A case of uterine perforation following attempted MTP at 14 weeks gestation was referred from a private clinic to our hospital in shock. On laparotomy uterine perforation at left lateral side of uterus was found with massive intraperitoneal bleed, hysterectomy was done after obtaining proper consent (Table 5). Most common intraoperative complication observed in this study was shock $(73.7 \%)$ followed by bladder injury, broad ligament hematoma and cervical injury. Posthysterectomy pyrexia (25.7\%) and DIC (21.4\%) were the two most commonly encountered post-operative complications. Maternal mortality following emergency obstetric hysterectomy occurred in 12 cases. Nearly $46.2 \%$ of neonates were admitted to the neonatal 
intensive care unit (NICU) primarily for birth asphyxia. Neonatal mortality observed in this study was $51.7 \%$ (Table 6).

Table 8: Type of hysterectomy.

\begin{tabular}{|lll|}
\hline Type of hysterectomy & Number (n), $n=56 \%$ \\
\hline Subtotal hysterectomy & 53 & $94.65 \%$ \\
\hline Total hysterectomy & 3 & $5.35 \%$ \\
\hline
\end{tabular}

Only $5.35 \%$ of cases underwent total hysterectomy in our study. In the remaining $94.65 \%$ sub-total hysterectomy was performed. Total hysterectomy was performed mainly for cases of low-lying placenta, adherent or extensive extension of the uterine angle involving the cervix, where removal of the cervix was considered mandatory for complete hemostasis (Table 8).

Two cases of obstetric hysterectomies (3.5\%) were performed due to torrential bleeding from placental bed following delivery of placenta in placenta previa. Sequential devascularisation of the uterus was performed in ten cases $(17.8 \%)$. B-Lynch sutures were applied in nine cases $(16 \%)$. Cervical, vaginal, or paraurethral tears were stitched in five cases $(8.9 \%)$.

Dopamine was used as the first-line agent to manage patient in shock. Adrenaline or noradrenaline infusion was added at the discretion of the senior gynaecologist or anaesthetist whenever required. Patients received transfusion of blood and blood products, as per requirement, ranging from one to 8 units, with an average of 3 units (Table 7).

\section{DISCUSSION}

Incidence of obstetrical hysterectomy in our study within 2 years of duration was $0.265 \%$ which was slightly higher to the studies conducted by Praneshwari et al, Sturdee and Rushton, Chew and Bishwas, Gupta et al, who reported an overall incidence of $0.0779 \% .^{5-8} 0.05 \%$. $0.0392 \%$ and $0.26 \%$, respectively. It may due to the fact that most of the deliveries at our tertiary care belong to high risk group and referral (higher in referral cases) (Table 2).

There was a high association of age in our study. Mean age of women who underwent obstetric hysterectomy at our centre was 25-30 years. In this study para 2 and para 3 patients had undergone maximum number of obstetric hysterectomies ie. 19 and 18 cases respectively (Table 3). Study conducted by Najam R et al revealed $29 \%$ cases with parity $>5.9^{9}$ The reason for this non-uniform distribution of parity with caesarean hysterectomy is due to presence of high risk factors elderly IVF pregnancies, ectopic pregnancy and other confounding factors such as low socioeconomic status, poor general condition, severe anaemia and massive hemorrhage Table 4.
In our study incidence of normal delivery was $56.4 \%$ and caesarean section was $43.6 \%$. Whereas, incidence of obstetric hysterectomy followed by vaginal delivery was $0.001 \%$ and obstetrical hysterectomy followed by caesarean section was $0.47 \%$ (Table 1 ). These results were slightly at a lower range as compared $0.0106 \%$, $0.039 \%$ of vaginal deliveries and similar to $0.33 \%, 0.45 \%$ in cesaerean section respectively as reported by Praneshwari et al, Pawar, Shroti et al. ${ }^{5,10}$

In our study most common indication for obstetrical hysterectomy was rupture uterus $(37.5 \%)$. Majority of ruptures are seen in previous scar uterus due to caesarean section (Table 5). Incidence in this study was higher to the study conducted by Kant A $(36.58 \%)$, Praneshwari et al, $(23 \%)$ and Vaidya $(20 \%))^{2,5,11}$ Second most common indication in our study was atonic PPH (25\%). Decrease in incidence of PPH in recent years is probably due to decreasing home deliveries by untrained persons and promotion and practice of hospital deliveries. Incidence of PPH in our study was higher to the incidence found by Praneshwari et al (19.2\%), Allahbadiya and Vaidya (16\%), and lower to Kant A et al $(41.46 \%)$, Agashe and Marathe (60\%) and Mantri et al (67.2\%)., 2,5,11-13

In this study maternal mortality was seen in (12/56) patients i.e (17.1\%) cases which was higher compared to results were found by Agashe and Marathe (14\%) (Table 6). Whereas, Praneshwari et al, found no maternal mortality in relation to obstetric hysterectomy. ${ }^{5,12}$ Primary reason for higher of maternal mortality in this study is non availability of ICU bed as there is common ICU for all the departments in our hospital. In our study most common type of hysterectomy performed was subtotal abdominal hysterectomy $(94.65 \%)$. Subtotal hysterectomy is usually preferred as it is less timeconsuming surgery and it gives a better outcome in a moribund patient. But in indications like placenta previa and adherent placenta total abdominal hysterectomy is the ideal treatment as it removes the bleeding placental bed in the lower uterine segment. At our centre $94.65 \%$ patients underwent subtotal hysterectomy which was higher compared to studies conducted by Praneshwari et al and Mrinalini et al (40\%) (Table 8). ${ }^{5,14}$

Amongst the post-operative complications, the most common post-operative complication in our study was fever seen in $(25.7 \%)$ followed by DIC (21.4\%), septisemia $(10 \%)$, wound infection $(10 \%)$, respiratory tract infection $(8.5 \%)$, and acute renal failure $(7.1 \%)$ (Table 6). Whereas, Praneshwari et al, found vesicovaginal fistula developed after subtotal hysterectomy which was done due to ruptured uterus following prolonged obstructed labor. ${ }^{5}$ Whereas, Kant Anita et al 2 found post-operative shock, pyrexia, paralytic ileus and wound infection as common postoperative complications. They were mainly due to prolonged labour, intrauterine manipulations and sepsis. Nazam R, reported 2 cases which had septic shock and 1 case in their study had DIC. ${ }^{9}$ 


\section{CONCLUSION}

EOH is a necessary evil in obstetrics. Although it curtails the future child bearing potential of the woman, in many cases it saves the life of the mother. Most of its morbidity is attributable to its indications and underlying disorders rather than to the procedure itself.

To conclude, our results demonstrated an increasing trend in the rate of Obstetric hysterectomy in parallel with an increasing rate of previous LSCS, emphasizing the importance of the mode of delivery. In spite EOH being a life saving measure, there occurs significant number of maternal deaths which can be prevented by good maternal care, active management of labor, early recognition of complications, timely referral, and easy availability of transport and blood transfusion facilities.

\section{Funding: No funding sources}

Conflict of interest: None declared

Ethical approval: The study was approved by the Institutional Ethics Committee

\section{REFERENCES}

1. Say L, Souza JP, Pattinson RC. Maternal near miss towards a standard tool for monitoring quality of maternal health care. Best Pract Res Clin Obstet Gynaecol. 2009;23(3):287-96.

2. Miller S, Lester F, Hensleigh P. Prevention and treatment of postpartum hemorrhage: new advances for low-resource settings. J Midwifery Womens Health. 2004;49(4):283-92.

3. Singhal S, Singh A, Raghunandan C, Gupta U, Dutt S. Uterine artery embolization: exploring new dimensions in obstetric emergencies. Oman Med J. 2014;29(3):217-9.

4. Varghese S, Gokulam N, Al- Abri S. Uterine artery embolization in postpartum hemorrhage: a case report. Oman Med J. 2012;27:2.
5. Praneshwari DRK, Singh N, Singh D. Emergency hysterectomy: a study of 26 cases over a period of 5 years. J Obstet Gynecol. 2004;54:343-5.

6. Sturdee OW, Rushton OI. Cesarean and post-partum hysterectomy. Br f Obstet Gynecol. 1986;93:270-4.

7. Chew S, Biswas A. Cesarean and postpartum hysterectomy. Singapore Med J. 1998;39:913.

8. Gupta S, Dave A, Bandi G. Obstetrichysterectomy in modern day obstetrics (a review of 175 cases over a period of 11years). F Obstet Gynecollnd. 2001;51:91-3.

9. Najam R, Bansal P, Sharma R, Agrawal D. Emergency obstetric hysterectomy: a retrospective study at a tertiary care hospital. J Clin Diagnost Res. 2010;4:2864-8.

10. Pawar PA, Shrotri A. Role of emergency hysterectomy in obstetrics. J Obstet Gynecol India. 1998;48:46-7.

11. Allahabadia G, Vaidya P. Obstetric hysterectomy (A review of 50 cases from January 1987 to August 1990). J Obstet Gynecol India.1991;41:634-7.

12. Agashe AP, Marathe SS. Obstetric hysterectomy (A review of 50 cases from January 1987 to August 1990). J Obstet Gynecol India. 1991;45:490:3.

13. Mantri L, Maheshwari K, Chandra. Emegency hysterectomy - A ten years review. J Obstet Gynecol India. 1995;43:936-9.

14. Mrinalini S, Manjusha J, Anjali K. Obstetric hystetrectomy: a life-saving emergency. J Obstet Gynecol Ind. 2008;58:138-41.

Cite this article as: Behera R, Rath B. Emergency obstetric hysterectomy: a two-year observational study at tertiary care center in Berhampur, Odisha, India. Int J Reprod Contracept Obstet Gynecol 2019;8:4695-9. 